\title{
Daniel Alcides Carrión y su Contribución al Imaginario Cultural de la Medicina Peruana
}

\author{
JUAN MURILLO ${ }^{1}$, OSWALDO SALAVERRY ${ }^{1}$, WALTER MENDOZA ${ }^{1}$, GUSTAVO FRANCO ${ }^{1}$, \\ WALTER CALDERÓN ${ }^{1}$, JUAN RODRÍGUEZ-TAFUR ${ }^{2}$ \\ ${ }^{1}$ Cátedra de Historia de la Medicina. Departamento Académico de Medicina Preventiva y Salud Pública. \\ ${ }^{2}$ Departamento de Ciencias Dinámicas, Facultad de Medicina de San Fernando - UNMSM.
}

\begin{abstract}
"Hace falta recurrir, entonces, a ese elemento vertebral del razonamiento histórico que es el método crítico: cotejar las fuentes, ponderar su veracidad, reconstruir los acontecimientos, establecer una cronología y al final no soslayar el juicio moral..." Alberto Flores Galindo, Buscando un Inca, 1986

"Daniel Carrión pertenece a esos seres a quienes está confiado hacer avanzar la especie humana bajo el signo de la razón."

Hugo Pesce, Carrión y su positivismo científico, 1957.
\end{abstract}

\begin{abstract}
RESUMEN
El estudio analiza el papel de Daniel Alcides Carrión como héroe cultural y elemento central de la tradición médica peruana. Se constata el proceso de elaboración del significado del experimento de Carrión en un escenario de lucha política y reconstrucción nacional que confluye con el positivismo de las élites aristocráticas del país de inicios de siglo. La recomposición social de las instituciones médicas y el ingreso del sector emergente a la Facultad de Medicina, hace que la imagen de Carrión creada a fines del siglo XIX se vuelva en la actualidad en un icono neutro, que puede ser absolutamente reivindicado por todos los sectores, al estar absolutamente arraigado en un pasado que no tiene presencia en el presente. Se hace un análisis del imaginario cultural que hizo posible el desarrollo de la Escuela Médica Peruana (1886-1956), período en el cual San Fernando produce la mayor cantidad y calidad de conocimiento médico realizado en el país. Se concluye que la confluencia de los siguientes elementos del imaginario médico local -Carrión como mito fundacional, resistencia emergente, proyecto de reconstrucción y restauración académica, ética y moral-, hizo posible la aparición de la Escuela Médica Peruana y, por ende, el mayor desarrollo y legitimidad social de la medicina en el Perú; y constituye la base para la construcción de una nueva cultura médica, en el marco de la refundación y construcción de un nuevo país.
\end{abstract}

Palabras clave: Historia de la medicina, Perú; escuelas médicas, Perú; Carrión, Daniel A.

\section{DANIEL ALCIDES CARRION AND HIS CONTRIBUTION TO PERUVIAN MEDICINE CULTURAL IMAGINARY \\ SUMMARY}

This study analizes Daniel Alcides Carrion role as a cultural hero and central element of Peruvian medical tradition. We verify the meaning of the elaboration process of Carrion's experiment in a political struggle and national reconstruction scenery that converges with the beginning of the century aristocratic elite positivism. Social recomposition of medical institutions and the emergent fraction entrance to the Faculty of Medicine makes end of the XIX century-Carrion's created image to become a neutral icon at the present time, amenable to absolute reivindication by all sectors as it is deeply rooted in the past with no current presence. A cultural imaginary analysis of Peruvian Medical School development (1886-1956) is done, as during this period San Fernando produced the country's largest and best quality medical knowledge. We conclude that confluence of local medical imaginary elements -Carrion as endowment myth, emergent resistance, academical, ethical and moral rebuilding, and restoration project- made possible Peruvian Medical School appearance; and consequently the development and social genuineness of Peruvian medicine, representing the foundation of a new medical culture within refoundation and building of a new country.

Key words: History of Medice, Peru; Schools, medical; Carrion, Daniel A.

Nota del Editor.- La publicación de trabajos por Anales de la Facultad de Medicina de San Fernando en sus diferentes secciones no involucra necesariamente solidarizarse con las opiniones vertidas por el o los autores.

Correspondencia:

Dr. Juan Pablo Murillo Peña

Apartado Postal 75. Lima 5, Perú

E-mail: epigroup@hotmail.com 


\section{INTRODUCCIÓN}

Daniel Alcides Carrión es la figura emblemática de la Medicina Peruana y, como tal, influye decisivamente en la institucionalidad académica del país a fines del siglo XIX y principios del siglo XX. La trascendencia de su acción es entendida como una mezcla de heroísmo y patriotismo. El dramático contexto de su experimento y posterior fallecimiento, además del consenso establecido en torno a la importancia de su aporte científico, lo han convertido en piedra angular de la tradición médica peruana, en ese sentido, Carrión cumple el rol de "héroe cultural", asignándole los logros paradigmáticos más importantes de la medicina local y tornándose en una referencia imprescindible en la identidad del colectivo. Sin embargo, como señala Nelson Manrique, a medida que pasa el tiempo, el héroe cultural que por definición es un símbolo, suele irse estilizando y perder las señas que constituyen su identidad primaria, en beneficio de identidades atribuidas, que expresan ante todo las carencias y las demandas de los hombres que las precedieron $\left({ }^{1}\right)$.

Asimismo, la reflexión en torno a la construcción de la imagen de Carrión nos permite estudiar la forma como se ha abordado el análisis histórico de la medicina en el Perú, el cual ha sido realizado mayoritariamente por médicos, principalmente durante las primeras décadas del siglo XX, quienes desarrollaron la disciplina como un esfuerzo de recuperación de una historia y cultura común, como eje de la consolidación de un colectivo médico, con el objetivo de lograr reconocimiento y legitimidad social $\left({ }^{2}\right)$. Este esfuerzo, a pesar de sus numerosos aportes, tuvo las limitaciones del contexto sociocultural en que fue desarrollado, tales como la ausencia de un marco teórico e instrumental de sustento al análisis histórico, de un énfasis en los elementos documentales y biográficos; además de un marco de referencia que presupone una "edad de oro" de la Facultad de Medicina, que se remonta al período entre la gestión de Cayetano Heredia y los meses previos al saqueo de la Facultad por los invasores chilenos durante la Guerra del Pacífico*.

Es en ese contexto que el abordaje del experimento de Carrión, como hecho concreto por parte de los primeros historiadores de la medicina, fue muy difícil, dada la tremenda carga emocional en torno al joven mártir que se inmolaba en medio del desastre de la guerra. En ese escenario, la posibilidad de formularse preguntas respecto a los acontecimientos ocurridos en torno a Carrión era sumamente limitada, por el enorme consenso en torno a su imagen de héroe cultural. De otro lado, existe hasta ahora toda una tradición, propia de la medicina local, que asigna una aureola santoral a los referentes señalados por una historia de tendencia hagiográfica y como lo señala García, una mal entendida sujeción a principios hipocráticos, que llevan a evitar el juicio crítico público al colega, tanto del pasado como del presente.

A pesar de la multitud de ensayos, discursos y recopilaciones documentales sobre Carrión, lo que no se ha conseguido hasta el presente es situar su experiencia en un contexto histórico que permita entender, explicar y derivar las consecuencias sociales que tuvo en particular para el colectivo médico. Han sido excepción los trabajos del Dr. Uriel García, dedicados a rescatar la identidad de Carrión frente al rol atribuido de héroe cultural y por tanto, exceptuado de todo análisis. Siguiendo esa línea, apelamos al análisis histórico que sintetizan Manrique y Flores Galindo, es decir, ubicar los aportes del joven mártir en el contexto de los conocimientos existentes en el colectivo que le tocó vivir, identificando el marco de los debates y luchas políticas en torno a las cuales se dio el experimento, evidenciando la trama de relaciones sociales e institucionales imperante y particularmente reconstruyendo los acontecimientos a la luz del análisis de los diversos hechos y discursos de los protagonistas. Consideramos que el material documental disponible, no ha sido adecuadamente analizado, en términos de tratar de lograr una explicación de los acontecimientos, por ataduras culturales e institucionales, especialmente presentes en la etapa de construcción de la imagen de héroe cultural de Carrión, las cuales se han perpetuado en una historiografía reciente carente de sentido crítico y repetidora incansable de tópicos aceptados como válidos por el colectivo médico.

Una consecuencia paradójica es que, a pesar del consenso respecto a la trascendencia del aporte de Carrión, éste es uno de los procesos históricos menos comprendidos. Y cabe preguntarse ¿Por qué es importante hoy un análisis crítico de los procesos socioculturales en torno a Carrión? Planteamos la hipótesis que el aporte de Carrión al imaginario cultural de la Medicina Peruana es un punto de partida para entender la crisis que padecen en la actualidad las instituciones médicas del país. El objetivo del presente estudio es hacer un análisis crítico de la contribución de Daniel Alcides Carrión al imaginario cultural de la Medicina Peruana y las consecuencias que se derivan de ello en la actualidad. Consideramos que dicho análisis nos proporcionará algunas claves o respuestas para la cons-

* Tal vez el término más adecuado sería, haciendo un símil con las edades del mundo griego, "La edad heroica”, donde los personajes todos, pese a su indudable corporeidad, son perfilados como seres de características sobrehumanas. Además debe considerarse que este período "heroico" se remonta, sin duda, en el imaginario propugnado desde la figura de Unanue. 
trucción de una nueva institucionalidad académica y una nueva cultura científica en el campo de la medicina, de cara al siglo XXI.

Para efectos del análisis de Carrión como hecho histórico y héroe cultural se ha revisado en forma sistemática las diferentes fuentes que por consenso han sido establecidas como de referencia para el estudio del problema planteado. Una fuente básica, diseñada para el análisis histórico y que reúne casi todos los documentos relevantes al experimento de Carrión y los hechos relacionados a su muerte, constituye la recopilación hecha por Valdizán $\left({ }^{3}\right)$. Las transcripciones de los documentos reunidos en el Museo de la Facultad de Medicina de San Fernando, que incluyen una importante correspondencia entre Carrión y sus familiares, han sido consultadas a partir de la publicación realizada con motivo de la apertura del Museo $\left({ }^{4}\right)$. En lo referente a catálogos historiográficos, se ha revisado el estudio hecho por Barandiarán $\left(^{5}\right)$, además de la exhaustiva bibliografía de Méndez $\left(^{6}\right)$. Se consultó asimismo una recopilación publicada recientemente por Delgado Matallana $(7)$.

También se consultó estudios que analizan algunas fuentes primarias, como el trabajo de Linares $\left({ }^{8}\right)$, además de una exhaustiva revisión de Lanfranco, que reúne mucha información de tipo familiar aparecida en la década del 50 $\left({ }^{9}\right)$. Dentro de los textos que han sistematizado información de tipo de histórico, se ha consultado los estudios de Rebagliatti $\left({ }^{10}\right)$ y Lastres $\left({ }^{11}\right)$, que sistematizan en conjunto la información que ha sido la base de los diferentes abordajes históricos realizados sobre Carrión. Asimismo se estudió diversas aproximaciones analíticas, realizadas por diferentes intelectuales a lo largo del siglo XX.

\section{LA FACULTAD DE MEDICINA Y LA GUERRA}

Un elemento fundamental para abordar el contexto de Carrión como hecho histórico es la Guerra del Pacífico. Este conflicto, marcó todo el paso del joven estudiante por la Facultad de Medicina, afectando progresivamente la vida académica del claustro universitario. En primer lugar, el Decano y los demás profesores cedieron sus haberes para que el gobierno los usara para la defensa del país. Posteriormente, la ocupación chilena de la capital significó, entre otras vejaciones, el saqueo de la Facultad. Avendaño, casi treinta años después, describe aquel panorama desolador:

"En esa mansión del saber donde los nombres queridos de Unanue y Heredia eran reputados como ángeles tutelares, allí en esa casa sagrada como un tabernáculo, se extremó la perfidia del invasor, y la piqueta demoledora destruyó en un momento la paciente labor de luengos años, que habian acumulado muchos y muy valiosos elementos de estudio, cual no los tenía en ese entonces, escuela mé- dica de la América Latina. Los magníficos laboratorios de química y farmacia, el espléndido gabinete de física, el riquísimo Museo de Anatomía Patológica, la valiosísima colección de piezas de cera, el bien montado Museo de Historia Natural (que contenía ejemplares que aún no han podido reemplazarse) y la gran biblioteca, la primera en su género en Sud América, que encerraba inestimables joyas y rarísimos ejemplares, todo, todo desapareció por completo. Los instrumentos y los útiles fueron destrozados, los frascos y las piezas de cera arrojados por las barandas del patio, los pergaminos seculares reducidos a cenizas, los libros ruinmente negociados en las tiendas de comestibles y el local convertido en escombros en un espantable cuadro de desolación y de ruina" $\left({ }^{12}\right)$.

La noche anterior a la ocupación de Lima, los archivos de la Facultad, así como los libros de matrícula, fueron trasladados a los domicilios del Decano Dr. Manuel Odriozola y de José Casimiro Ulloa. Sebastián Barranca, en un gesto heroico ahora olvidado, logra salvar algunas colecciones del Jardín Botánico y de la Biblioteca. En una decisión que requirió un tremendo coraje y amor por el país y la universidad, los miembros de la comunidad sanfernandina (autoridades, profesores y alumnos) decidieron continuar las labores académicas en la clandestinidad. El Decano instaló la secretaría de la Facultad en un humilde local en la calle Núñez y dispuso que las clases se dictasen en las casas de los profesores; incluso se realizaron matrículas y exámenes. Ello permitió la normalización de las labores académicas una vez retirado el invasor de la capital. En ese escenario de clandestinidad, Carrión cursó del segundo hasta el cuarto año de medicina.

El escenario político de la posguerra inmediata fue el enfrentamiento entre Iglesias, firmante de la paz con Chile, y Cáceres, quien junto con las masas campesinas había salvado el honor de las armas peruanas al conducir la resistencia al invasor en los Andes $\left({ }^{13}\right)$. Este contexto de guerra civil planteó un escenario autoritario, que afectó pronto a la Facultad de Medicina. El gobierno de Iglesias nombró a un profesor afín a éste, lo que motivó la oposición del decano Dr. Odriozola, el cual fue destituido y enjuiciado por desacato. Ante ello, el cuerpo docente, aquel que había resistido al invasor y que había realizado el máximo esfuerzo para que la Facultad sobreviva al desastre de la guerra, renunció masivamente en respaldo al decano, siendo reemplazado por profesores afines al régimen.

Todo este escenario necesariamente debió afectar a Carrión, quien junto a su hermano Teodoro que estudiaba en Lima sufría la falta de alimentos, las carencias económicas, el ambiente hostil de la ciudad y la guerra civil. El 24 de agosto de 1884, Carrión como interno del Hospital San Bartolomé atendió a los heridos que dejaron los encarnizados combates del primer intento de captura de Lima 
por Cáceres. En una carta enviada a Alejo Valdivieso, fechada el 4 de julio de 1885, Carrión le manifiesta lo siguiente:

“En política hay muchas novedades, pero desgraciadamente, nada puedo decirle por temor. Cerraron la imprenta de 'El País' por su juicioso editorial. Al Comercio le pusieron una fuerte multa de 500 soles de plata por publicar noticias del interior. No sé cuál será el curso que tomen las cosas en el presente mes. Todo está hoy por hoy muy oscuro y muy misterioso..." $\left({ }^{14}\right)$.

En julio de 1885 , Cáceres se consolida definitivamente en la región central del país, interrumpiendo las comunicaciones entre la sierra y la costa. Esto ocasionó un grave problema a Carrión, por su dependencia de las mesadas que le enviaba su padrastro de Cerro de Pasco. En ese sentido, le escribe una carta a Alejo Valdivieso, donde le manifiesta:

"Mi padrino todavía no ha llegado y creo que no podrá hacerlo por Chincha puesto que el gobierno ha ordenado que no haya tráfico por esa línea. Han llegado algo de las tropas del interior, así como heridos y enfermos. Creo que todas las tropas se reencontrarán en Lima, puesto que hasta las del norte han sido pedidas. Más, es siempre más. Esta falta de comunicación con el Cerro va a ser de bastante embarazo para nosotros. ¿Qué hacer? Paciencia y barajar..." $\left({ }^{15}\right)$.

Pese a lo afirmado en la carta glosada anteriormente, hay indicios de que Carrión ya había perdido la paciencia. Aparentemente a fines de 1884 , le escribió una carta a su padrastro, la cual no ha sido ubicada, pero por el tenor de la respuesta, se deduce la intención de Carrión de continuar su formación en el extranjero, como algunos de sus condiscípulos de familias más acomodadas. Alejo Valdivieso le responde: "Ya comprendo del asunto de que me hablas, de acabar tus estudios en Europa en donde sin esfuerzo conozco sus ventajas, pero debo decirte que en las actuales circunstancias de crisis no es posible pensar en ello..." Es posible que Carrión le haya planteado sus reservas respecto a las condiciones de estudio en la Facultad, su pobreza y falta de medios, además de las limitaciones de los nuevos docentes, frente a lo cual su padrastro le responde: “... Tu estudias felizmente hasta ahora con buen éxito y es prudente seguir en Lima donde es más posible sostenerte y de donde han salido también médicos de pri- mera clase" $\left({ }^{16}\right)$. Se deduce de este incompleto intercambio epistolar, el interés de Carrión de sustraerse del escenario de crisis local y terminar sus estudios en Europa en mejores condiciones y la imposibilidad de Alejo Valdivieso de financiar dicho viaje por el incierto panorama social y económico.

\section{EL EXPERIMENTO DE CARRIÓN}

En el difícil escenario de la post-guerra se genera dentro de la Facultad de Medicina un fenómeno de resistencia colectiva, como respuesta a la intervención de la Facultad, su estado de destrucción física y colapso institucional. Se expresa en la fundación de la "Unión Fernandina", un grupo estudiantil que decide impulsar un proceso de modernización mediante el desarrollo de actividades extracurriculares y principalmente en la difusión y promoción de la investigación, a través de veladas científicas.

Fuera del ámbito estudiantil, estaba claro que el conflicto en la Facultad había alejado de ésta a un sector del colectivo médico, quienes por su trayectoria y prestigio, además de su resistencia al invasor, podían considerarse tributarios del proyecto de modernización de Cayetano Heredia, y por ello era esperable que los vientos renovadores o restauradores se iniciaran por fuera de la institución. Es así que, el 29 de julio de 1885, después de varios meses de preparación, los profesores renunciantes fundaron la "Academia Libre de Medicina", la cual pretendía encarnar la continuidad histórica y cultural del colectivo sanfernandino. La naciente Academia Libre apela al discurso cultural positivo, como un elemento de deslinde respecto a la Facultad oficial. Ello era un elemento tan central, en la forma como la Academia configuraba su estrategia de confrontación, que en la sesión de constitución de la misma se presentó una moción presentada por los académicos Leonardo Villar, Miguel Colunga y Belisario Sosa, planteando la convocatoria a un concurso científico, propuesta que fue aprobada por unanimidad $*\left({ }^{17}\right)$.

Carrión no estaba al margen de este proceso, a pesar de que es un punto pendiente de indagación por qué éste no se incorpora a la Unión Fernandina, la cual aglutinaba a un sector importante del estudiantado. En ese contexto, se ha planteado que existen indicios que Carrión era marginal a la trama de instituciones que surgían como respuesta al conflicto institucional y eventualmente político

\footnotetext{
* "En virtud de estas consideraciones, la comisión de concursos que suscribe, dando preferente importancia al estudio de las verrugas, somete a la consideración de la Academia el siguiente proyecto:

Artículo 1. La Academia Libre de Medicina, en conformidad con el artículo 73 del reglamento orgánico, convoca a un concurso que tendrá lugar en Julio de 1886 para el estudio de la etiología de la Verruga, de su Anatomía Patológica y su distribución geográfica. Artículo 4. El premio ofrecido al autor de la memoria que se considere merecedor de él, consistirá, además del diploma en una medalla de oro, en cuyo mote se designará el mérito obtenido."
} 
$\left.{ }^{18}\right)$. Sin embargo, en una colectividad académica sumamente pequeña era muy difícil que este evento pasara inadvertido. Los hechos demuestran, que evidentemente tomó la decisión de participar con una propuesta, a los términos de la convocatoria de la Academia.

Si Carrión realizó un diseño o plan, éste no llegó hasta nosotros. Lo que se desprende del análisis de las notas recogidas por sus condiscípulos, es que éste planteaba la hipótesis de que la verruga era inoculable. En ese sentido no existe evidencia de cualquier actividad preparatoria. El hecho es que el 27 de agosto de 1885, en el Hospital Dos de Mayo, se procede a la inoculación en base a las verrugas del enfermo Carmen Paredes, que ocupaba la cama número 5 de la sala de Nuestra Señora de las Mercedes.

De acuerdo al testimonio de Leonardo Villar, tenemos una versión de cómo se inicia el experimento de Carrión:

"El 27 de agosto último, Carrión se presentó nuevamente a una de mis salas, estaba poseído de una incuestionable decisión de inocularse, esta vez no fue posible hacerle desistir. Por más que el Dr. Chávez y yo intentamos disuadirle a las observaciones que hicimos, contestó con estas palabras: 'Suceda lo que sucediese, no importa, quiero inocularme', de este hecho son testigos alumnos del servicio interno Don Julián Arce y el externo don José Sebastián Rodríguez. Una vez así, se desprendió de nuestras advertencias, se descubrió el brazo y armado de una lanceta de vacunas que había llevado consigo, trató de hacerse la inoculación en la parte superior y anterior del brazo izquierdo, fue entonces que el Dr. Chávez, viendo que era inconveniente hacerse una picadura en esa localidad y a fin de evitar que Carrión se hiciera un daño involuntario al operar en sí mismo, le tomó la lanceta e hizo la inoculación en el sitio común de la vacunación. Yo me hallé en ese momento en la sala..." $\left({ }^{19}\right)$.

Los primeros días seguidos a la inoculación transcurrieron sin mayores molestias. El día 8 de setiembre, Carrión le dirige una misiva a su madre en términos muy cariñosos, pero concisos, especificándole que está muy “apurado por sus estudios”. Según Lanfranco, en la misiva se revela serenidad, seguridad en sí mismo y optimismo respecto a su salud; incluso le señala que irá a verla a Cerro de Pasco al terminar los exámenes del sexto año de estudios $\left({ }^{9}\right)$. En términos generales, Carrión no manifiesta mayores molestias durante los 22 primeros días posteriores a la inoculación. El día 19 de septiembre, los síntomas aparecen de manera súbita, con fiebre intensa y gran compromiso del sensorio.
El día 26 de septiembre, 30 días después del experimento, Carrión le escribe una carta a su padre donde le cuenta que está convaleciente, comunicándole el retiro de la fiebre y solamente el mantenimiento de un "derrame ictérico" y algo de inapetencia, refiriéndole además que pensaba suspender el tratamiento con sulfato de quinina y salicilato de sodio $\left({ }^{20}\right)$. Sin embargo, el diario del experimento identifica dicho día como el punto de empeoramiento de los síntomas. Probablemente la percepción de deterioro del joven experimentador lo llevó a escribir a su padre, aunque todavía del tenor de la misiva se traslucía su esperanza de lograr una pronta recuperación. A partir de dicho día, la observación sería conducida por sus condiscípulos. El día 28 de septiembre fue evaluado por primera vez por un facultativo, el Dr. José María Romero.

El día 2 de octubre, según lo manifestado por sus condiscípulos, Carrión, a pesar de su condición tan venida a menos, llega a la conclusión de que es portador de La Fiebre de la Oroya $*\left({ }^{21}\right)$. Ese día es evaluado por una junta médica conformada por los Drs. Villar, Macedo y Chávez. Su estado se sigue deteriorando hasta que, el 4 de octubre, es trasladado al Hospital Francés, donde se reúne una junta médica formada por los Drs. Villar, Romero, Flórez y Chávez. A pesar del consenso para realizar una transfusión de sangre, por razones que se desconoce, se aplaza la intervención, falleciendo Carrión a las 11:30 de la mañana del 5 de octubre de 1885 .

\section{ANÁLISIS CRÍTICO DE LA EXPERIENCIA DE CARRIÓN}

Un aspecto analizado por Uriel García, es el tipo de propuesta planteada por la Academia para el concurso. Cuando se refieren a la etiología de la Verruga, dentro del contexto de las corrientes conceptuales en que se movía la colectividad médica local, se referían a una etiología microbiana. Realizar investigaciones microbiológicas en el Perú de 1885 era poco menos que imposible, dado que no se enseñaba bacteriología en la Facultad y no se disponía además de los medios necesarios. Respecto a la Anatomía Patológica, tampoco existía la enseñanza de la histología ni medios para poder realizar un trabajo relevante, más aún en medio de la gran carencia de medios materiales y económicos para emprender una investigación de ese tipo. Era evidente que, en plena guerra civil, era imposible estudiar la distribución geográfica de la enfermedad; más aún, ello implicaba un despliegue de recursos y tiempo fuera del alcance de cualquier institución académica del país. La pregunta que se plantea es: ¿Los

* Sus compañeros describen lo siguiente: "El rostro desencajado, los ojos, hundidos y rodeados de un círculo negruzco, las mejillas y las sienes completamente deprimidas, la nariz afilada y los pabellones auriculares casi transparentes..." 
miembros de la Academia Libre eran lo suficientemente desconocedores de la realidad científica del Perú como para convocar a un concurso en el cual era imposible que alguien participara?. Se supone que el concurso era parte de la estrategia de posicionamiento social e institucional de la Academia, por lo que si en algo tenían interés, era que el concurso tuviera éxito.

En ese contexto, la única forma de estudiar la etiología de la enfermedad, era mediante una forma indirecta y creativa de obtener conocimiento relevante, como la inoculación. Para llegar a una decisión de este tipo se requeriría de una visión del escenario local, además del conocimiento de las posibilidades de la inoculación como una técnica de investigación válida. Si bien la autoinoculación era una práctica extendida dentro de la tradición científica europea de la segunda mitad del siglo XIX, no sabemos si Carrión pudo haberse familiarizado lo suficiente con ella como para plantearse el desarrollo de una experiencia viable. La pregunta que surge es si Carrión manejaba la suficiente información y red de relaciones para poder haber realizado este proceso de análisis, tanto en el campo de la teoría como en el de viabilidad de la experiencia $*\left({ }^{22}\right)$. Bajo la hipótesis de que el 29 de julio Carrión se entera por primera vez de las bases del concurso, hasta la fecha de la ejecución del experimento el 27 de agosto, se plantearía que en menos de 30 días Carrión habría realizado todo este proceso. ¿Pudo un estudiante provinciano, sin mayores recursos económicos, con un limitado acceso a información relevante, sin una trama importante de relaciones sociales, implementar la experiencia en tan poco tiempo?.

Tradicionalmente se ha aceptado las historias clínicas recopiladas por Carrión como evidencia de que estaba trabajando en su tesis de bachiller. Las observaciones y comentarios señalados en ellas no nos conducen necesariamente a plantearnos la necesidad de un experimento de inoculación. El hecho objetivo es que, en 30 días, Carrión tuvo que hacer muchísimas cosas, desde hacer un análisis del escenario local y la propuesta del concurso, diseñar o imaginar la experiencia, seleccionar a los pacientes y preparar las condiciones de la observación, lo que implicó el apoyo organizado de sus compañeros. Cabe señalar aquí que Carrión se sostenía con una mesada que apenas alcanzaba para sus necesidades y las de su hermano, lo que implica que tuvo de alguna manera, que tomar previsiones económicas para afrontar los gastos adicionales en su manutención que generaría el experimento y que no estaba en condiciones de asumir, dada su estrechez económica; todo ello, además, en el contexto de un escenario de convulsión institucional y social.

De otro lado, es muy casual que Carrión intentase inocularse en el mismo servicio del miembro de la Academia que promueve el concurso. Es interesante que el Dr. Villar insinuase que no fue la primera vez que Carrión intentó la inoculación, lo que implica, que el período de preparación de la experiencia fue menor de cuatro semanas. De otro lado, Villar declara que no pudo hacer nada por impedir la inoculación, lo cual no es tan creíble, teniendo en cuenta el poder casi omnímodo que tenían los jefes de servicio de la época, a semejanza del "patrón" del hospital francés.

De otro lado, el vocero escrito de la Academia Libre de Medicina, el Monitor Médico, publica la siguiente nota titulada "La Verruga":

"Con motivo de algunos casos de esta enfermedad que se han presentado en el Hospital Dos de Mayo alguno de sus alumnos que se ha consagrado a su estudio no ha vacilado en practicarse una inoculación en la sangre de un tumor de un enfermo. La experimentación tan atrevida como paciente es seguida con la mayor atención y del resultado daremos oportunamente cuenta..." $\left.{ }^{23}\right)$.

El Comercio en una nota titulada publicada el 29 de agosto de 1885, refiere lo siguiente:

"El estudiante de medicina, señor Daniel Carrión, el cual tiene trabajos adelantados sobre la enfermedad llamada 'berrugas', se ha hecho inocular ayer la sangre de un berrucoso para observar por sí mismo los efectos de la inoculación y resultados ulteriores de esta enfermedad indígena del Perú, que tanto preocupa la atención de los hombres de ciencia en Europa... La inoculación fue hecha por el Dr. Chávez en la sala de Mercedes, departamento del Dr. Villar, hospital 'Dos de Mayo', tomando la sangre de la misma verruga e inoculándola por cuatro incisiones en el brazo y antebrazo izquierdo y derecho, la marcha ulterior de esta operación experimental será seguida indudablemente con ansiedad y sus resultados tendrán que ser de gran provecho para la ciencia médica nacional..." $\left.{ }^{24}\right)$.

* Monge, al analizar cómo pudo Carrión concebir su experiencia, refiere: “A tal planteamiento -decía yo en 1925- sólo pudo llegarse al conocer profundamente la materia, lo que permitió al hombre de ciencia fijar los términos y las incógnitas del problema. Las hipótesis de trabajo no son juegos de azar, sino fruto de muy largas meditaciones, que hubo de hacerlas del año 1883 al de 1885 , como aparece de las fechas de sus historias clínicas. Evidentemente, llegó a adquirir la máxima sabiduría de su época sobre el tema..." Monge al tratar de entender el proceso de construcción del experimento de Carrión con nuestros propios códigos culturales muestra, sin proponérselo, las limitaciones que habría tenido Carrión para abstraer y diseñar por sí solo un experimento de inoculación de posibles agentes infecciosos durante aquel difícil período. 
Posteriormente vienen los eventos relacionados con la enfermedad misma de Carrión. Aquí existen elementos muy contradictorios. El relato del experimento nos muestra un investigador seguro de sí mismo, objetivo y heroico, muy diferente al estudiante lleno de dudas e incertidumbres que se refleja en las cartas. Es curioso, por decir lo menos, que en el relato escrito por sus compañeros no aparezca alguna inquietud de Carrión respecto a su familia, ninguna preocupación respecto al país, cosas que evidentemente eran centrales en las inquietudes del joven mártir. Ello apunta, en el mejor de los casos, a que el relato fue cuidadosamente construido, apuntando a la construcción de una imagen heroica de Carrión.

En dicho testimonio se ve que los Drs. Villar y Chávez no fueron a evaluar a Carrión, sino hasta una etapa muy avanzada de la enfermedad. ¿Por qué, si Carrión se había inoculado en su servicio, no tomaron interés en seguir de cerca la evolución del caso? ¿No era ello un hecho científico que merecía ser visto de cerca? ¿Acaso Carrión no se había inoculado en su servicio y por ende tenían la obligación ética de brindarle asistencia? Pareciera que el relato estuviera orientado a marcar una distancia entre Villar y Chávez (y por ende de la Academia) y el desarrollo de la experiencia. Si el experimento, según la nota del Monitor Médico, era seguido "con minuciosa atención" ¿por qué los testimonios no registran visitas de miembros de la Academia hasta etapas muy avanzadas de la enfermedad? Luego viene la muerte de Carrión, donde la Academia respalda y reconoce el sacrificio del joven estudiante, frente a una Facultad insensible e intolerante $*\left({ }^{25}\right)$.

Si el sacrificio de Carrión fue tan importante en la Medicina Peruana, si muchos de sus compañeros de promoción o condiscípulos de otros años fueron profesores de la Facultad, algunos con un gran reconocimiento institucional y social, como Ernesto Odriozola o Julián Arce, ¿por qué no existen mayores testimonios, una memoria generacional que pueda haberse transmitido en el curso de las clases, conferencias o discursos al respecto? ${ }^{\dagger}\left({ }^{26}\right)$ Parece que toda la memoria sobre Carrión empieza y termina en el opúsculo impreso en la Imprenta del Estado, lo cual es sumamente extraño, dado que si el experimento de Carrión es el mito fundacional de la escuela médica peruana, es lógico que hubiera un mayor interés en conocer los detalles de la epopeya, más aún en un país sin tradición en el campo de la medicina experimental.

Por todo ello, planteamos la hipótesis de que el experimento de Carrión fue promovido por la Academia Libre de Medicina. La Academia a través de la propuesta de concurso (y probablemente del experimento) realizada por Villar, crea todas las condiciones para que Carrión, un estudiante provinciano, alejado de su familia y lleno de incertidumbres respecto al futuro, en un tiempo muy corto, pueda realizar la experiencia y pueda ésta tener una base de aceptación y visibilidad social. El éxito de la experiencia le permitiría a la Academia el mérito de ser reconocida como la promotora del desarrollo científico de la medicina local, logrando una importante victoria en el campo de la hegemonía cultural dentro del conflicto entre la periférica Academia que agrupaba a los herederos de la tradición de Heredia y la oficialista Facultad de Medicina.

Es evidente que dentro de las hipótesis de partida que se manejaron, no estaba el deterioro ni la muerte del joven estudiante $\ddagger$. Ante la imputación criminal de la prefectura, por un lado la Academia toma distancia, planteando la iniciativa personal de Carrión y sosteniendo el carácter científico de la experiencia. Sin embargo, la Academia en ningún momento declara a Carrión ganador del concurso,

* La Facultad de Medicina expresó su enérgico rechazo frente al trágico experimento, del cual hacía responsable a su rival en el plano político, la Academia Libre de Medicina, en la persona del Dr. Villar; ello se expresa meridianamente en la posición de Ignacio la Puente, Secretario de la Facultad de Medicina, quien en un ensayo publicado el 6 de octubre de 1886 plantea lo siguiente:

"Deploramos profundamente que esta operación de patología experimental se haya hecho sin tomar las precauciones que, asegurando el resultado que se perseguía, garantizase la completa inocuidad.

"Tomar la sangre de una verruga, inocularla directamente, sin previo estudio del microbio, sin cultivarlo en líquidos que atenuasen su vigor y sobre todo, lanzarlo al torrente circulatorio de un hombre, venga lo que viniere, sin experimentación anterior en animales, como está mandado en tales casos, es una audacia temeraria, poco científica y de tristísima celebridad para sus autores.

"La ciencia ha ganado poco, el desprestigio profesional ha aumentado y la preciosa existencia de un joven incauto ha sido arrebatada con falta de aquellos que debieron disuadirlo en vez de alentarlo en tan peligrosa vía..."

$\dagger \quad$ Un ejemplo de ello lo constituye la clase que dicta el Dr. Julián Arce en la Cátedra de Enfermedades Tropicales, curso de 1917, donde a pesar de ser compañero de promoción, testigo de la inoculación y haber atendido a Carrión en todo el proceso, hace una referencia muy fría, impersonal y escueta a Carrión, puntualizando el origen de la hipótesis de la unidad etiológica de la Fiebre de la Oroya y la Verruga Peruana en los planteamientos del Dr. Espinal, en 1871.

$\ddagger$ En su testimonial en el proceso judicial que siguió a la muerte de Carrión, Villar declara que el resultado del experimento no se pudo prever puesto que "no había ningún antecedente conocido para la doctrina..." 
el cual fue declarado desierto por falta de postulantes * $\left.{ }^{(27}\right)$. Es evidente que existe una actitud ambivalente de esta última; por un lado hace suyo el sacrificio de Carrión mitificándolo y por otro, toma distancia del experimento, cuestionando incluso su carácter científico ${ }^{\dagger}\left({ }^{28}\right)$. ¿Acaso asociar a Carrión al concurso no iba a aumentar el prestigio de la institución? Es evidente que existe un doble discurso; por un lado la Academia toma distancia del experimento descalificándolo y por otro, coloca la experiencia dentro de la tradición cultural de occidente e impulsando la construcción de la imagen de Carrión como héroe cultural. Ello revela una intención sistemática de asociar la imagen del mito a la corriente cultural que encarnaba la Academia como parte de la lucha por el poder, actitud que para nosotros, constituye un claro indicio de un nivel de manipulación de los hechos.

Otro elemento crítico en el análisis y que además ha sido soslayado por la mayoría de investigadores es la idea de la inoculación. La inoculación en sí misma es un tipo de experiencia que requiere un importante nivel de abstracción respecto al objeto de estudio. Las observaciones recogidas por sus condiscípulos no recogen reflexión alguna que conduzca o plantee la necesidad de una inoculación. Este es un elemento central, dado que si Carrión estuvo trabajando en la idea, debió haber dejado un escrito al respecto, siguiendo la lógica de las historias clínicas tan pulcramente descritas por él. Es un año después, en un discurso de homenaje pronunciado por su condiscípulo Mariano Alcedán en la "Unión Fernandina”, que se brinda un "testimonio" $\left({ }^{34}\right)$, que más que mostrarnos una visión directa del joven mártir, está orientada a llenar vacíos importantes en la construcción del mito:

"Muchas veces le oíamos preguntar: ¿La verruga es infecciosa? - ¿Es inoculable?...”

"A lo primero nos decía: Creo en la infecciosidad de la verruga, pues en los lugares donde reina endémicamente, raros son los que escapan a su letal influencia; vemos en los rumiantes y paquidermos sufrirla, dando lugar a la forma que vulgarmente se llama verruga mular”.

"Me parece que los efluvios se formarían en esas regiones lo mismo que los palúdicos: descomposición de las materias vegetales, sirviéndolas de continente el agua, que bajo la influencia de condiciones climatéricas especiales y las variadas manifestaciones del nivel de las aguas, podrían elevarse a cierta altura en la atmósfera. Si no ¿Cómo explicarse que las aguas del Rímac en unos lugares sean productoras de verrugas y en otras no? ¿Cómo responder, por otro lado, a aquellos individuos que habiéndose sustraído de la influencia del agua, sin embargo hayan sido atacados por la verruga?"

"Se ha creído, hasta hoy, que la verruga no era inoculable, afirmación que, careciendo de pruebas, no merece más respeto que la autoridad donde emana”.

"Tengo noticia de la descripción hecha por el doctor Izquierdo, con preparaciones hechas de piezas conservadas alcohol, que desde acá le habrían remitido, en que se describe un microbio especial a la verruga, asignándole un tamaño máximo de 20 n.mm., un poco más grueso que el bacilo de la tuberculosis, asignando a los tumores el carácter general de sarcomas, que tendrían lugar de formarse en el tejido conjuntivo. En cuanto a su residencia en el tejido conjuntivo, no es nueva, pues ya el doctor Vélez la había emitido. Dadas las circunstancias en que esta observación se ha producido, de un lado y de otro, el no haber cultivado ni comprobado por inoculaciones, que sea lo visto y descrito por él como microbio patógeno, hacen muy sospechosa su admisión, tanto más cuanto por el prurito que hoy se tiene de señalar microbios para todas las enfermedades".

"Se ha dicho y sostenido, por algunos, que la Fiebre de la Oroya y la Verruga reconocen el mismo origen, pero estas aseveraciones se encuentran desprovistas de hechos que, poniéndolas de manifiesto, le sirvan de fundamento para su admisión en la ciencia”.

* Una idea de la forma epidérmica con que la Academia manejó el análisis concreto de los hechos evidenciados por el experimento de Carrión en torno a la Enfermedad, lo muestra de manera meridiana una intervención del académico Dr. Rosas un año después de los acontecimientos, quien luego de escuchar diversas manifestaciones en torno a la verruga cuando se discutía el cuestionario para un nuevo concurso, planteó lo siguiente según el registro de actas de la sesión:

"El Dr. Rosas manifestó el interés que le inspiraba la Academia; que lo que primero debía hacerse era averiguar la causa por qué no había habido concurso el año pasado; que por lo que acaba de oír, se ignoraba todo respecto de la enfermedad de la verruga; que era más conveniente nombrar una comisión ó una persona que fuese a estudiar la enfermedad en los puntos donde nace; que esto era difícil sin el apoyo del Gobierno; terminó manifestando que no estando preparado el terreno tal vez no tendría lugar el segundo concurso, debiéndose antes reunir los elementos, haciendo los estudios preparatorios..."

$\dagger \quad$ Luego que la Academia, a través del Monitor Médico, diera a conocer el experimento realizado y señalara en la nota su seguimiento de la experiencia con "minuciosa atención", en un editorial días antes de la apertura del juicio sostiene: "Pero esta inoculación se hizo desautorizada, o por lo menos, no se siguió el consejo de los hombres serenos que nunca hubieran permitido un experimento que descuidó todo principio científico..." 
Este discurso ha pasado totalmente desapercibido y muestra el contraste entre el estudiante lleno de inseguridad y temores de sus cartas, el héroe altivo y sereno de la inoculación y el Carrión positivista que aparece en este discurso. La primera pregunta que aparece en este punto es: ¿Estamos hablando de una multidimensionalidad del personaje, o realmente estamos frente a imágenes diferentes? *. Existe una gran distancia entre el minucioso observador de las historias clínicas y el relato del discurso donde el joven estudiante aparece teorizando sobre espacios ecológicos de exposición, evidencia patológica y microbiológica, estableciendo incluso criterios epistemológicos de verdad. ¿No suena un tanto excesivo para un estudiante, sin acceso a fuentes de información y, como lo sostiene García, marginal a los circuitos sociales y académicos de la Facultad? ¿Por qué estas observaciones, que se dicen tan ampliamente discutidas a nivel del pequeño colectivo Sanfernandino no aparecen en el texto preparado por sus condiscípulos?

Este discurso revela un hecho, también desapercibido. Inmediatamente después de la muerte de Carrión, se le extrajo sangre que sirvió para la inoculación de dos conejos, lo cual dio resultados fallidos. ¿A quién en un momento tan dramático como era la muerte del joven estudiante, se le ocurriría continuar con la observación experimental? ¿Quién dispuso de su ejecución? Es evidente que en torno a Carrión existía más que una red de asistencia, sino un grupo que estaba pensando y actuando en torno a la observación experimental. Un indicio que confirma la existencia de este conjunto de acciones concertadas, es el hecho de que los médicos de la policía que investigaron el caso no tuvieron acceso al diario del experimento, el cual fue puesto a bien recaudo de las pesquisas, tanto de la policía, como de la Facultad.

Es evidente que la forma tan rápida con que se dieron los hechos, la concepción y organización de la experiencia, la forma como se dieron los acontecimientos y el conjunto de hipótesis y análisis atribuidos a Carrión, rebasan las posibilidades de acción solitaria del joven estudiante. De otro lado la inoculación en sí estuvo concebida para tener una capacidad convocante para la colectividad médica nacional e internacional; en función de los referentes culturales con que se manejaba la ciencia en aquél tiempo.
Todo ello nos plantea la siguiente pregunta ¿Quién pudo tener la capacidad para delinear dicho escenario?

En este punto, las evidencias nuevamente apuntan a Villar. En su descargo ante el inspector de la Policía manifiesta lo siguiente:

“Aquí podría terminar, señor Inspector, este informe; pero deseando manifestar la importancia y el prestigio que en países civilizados merecen los actos como el acometido por el malogrado joven don Daniel Carrión, voy a citar algunos hechos de esa misma naturaleza, que se hallan consignados en las obras y en los periódicos de Medicina y que son desconocidos por los médicos menos ilustrados. Estos hechos han sido siempre considerados como hechos de grandeza del alma y no como viles medios de homicidio o de suicidio."

"La cuestión tan debatida, del contagio de la sífilis en sus formas secundarias y terciarias, fue resuelta -como dice el profesor Bouley- por un golpe de lanceta, dado por el profesor Gilbert, de la Academia de Medicina de París, haciendo inoculaciones en el mismo hombre".

"En la obra de 'Patología Externa' de Follin, se habla de un estudiante que, a la vista del profesor Rayer, se inoculó el líquido de una pústula maligna... En la última epidemia del Cólera en Egipto, el célebre doctor Koch hizo al Doctor Strauss, una inyección intravenosa de la sangre de un colérico. Esta inyección produjo la muerte del Dr. Strauss, sin embargo nadie calificó este acto de homicidio..."

"Por estas citas, cuyo número podría aumentar inmensamente, trayendo a cuenta las inoculaciones hechas en el hombre con el Cáncer, con la Difteria, etc., se ve que hay seres superiores, de espíritu fuerte, que cuando van en pos de la verdad o de un hecho útil a la humanidad, se sacrifican y arrostran a todo peligro. A esos hombres, a quienes la conciencia universal los llama héroes, es injustificable tildarlos con el estigma de criminales o incautos."

En la defensa que esgrime Villar, se observa que había alcanzado un gran nivel de comprensión de la inoculación como método experimental ${ }^{\dagger}\left({ }^{30}\right)$, pero por sobre todo, como una corriente cultural, lo cual es una constante en la

* El relato del discurso integra además un componente de antichilenismo, al sostener la oposición de Carrión a las observaciones de Izquierdo, que completa la figura en los términos de una sociedad golpeada por la guerra y al que se le ofrece un mito que reúne el sacrificio por la ciencia (la promesa del desarrollo a través de la ciencia y la técnica promovida por los positivistas criollos) y el patriotismo de quien quiere evitar una nueva afrenta del invasor.

$\dagger$ Leonardo Villar estuvo durante años reflexionando sobre el tema. No sólo fue miembro de una comisión nombrada por la Facultad de Medicina para el estudio de la epidemia de 1871, sino que en abril del mismo año realizó un experimento, analizado recientemente por García. 
posición de la Academia respecto a Carrión. Ello confluye con su propuesta de concurso donde, como se observó anteriormente, apuntaba directamente a un estudio de este tipo.

En conclusión, es perfectamente claro que el experimento de Carrión se inserta en la tradición de la medicina experimental europea ${ }^{31}$ ); pero, ¿cómo Carrión tuvo acceso a ello? Si bien luego de la guerra llegó una gran cantidad de información de los avances de la medicina experimental europea, un porcentaje importante de ella no estaba a su alcance. Es evidente que requirió discutir este problema con médicos más informados (los cuales eran una minoría en esa época), en la medida que sus condiscípulos tenían los mismos problemas de acceso a información.

El hecho del experimento mismo plantea otro tipo de problemas, ¿por qué Julián Arce, que fue testigo de todo el proceso, con mayores medios tecnológicos y con una base de conocimiento bacteriológico y evidente interés en el tema de la verruga, no desarrolló mayores investigaciones al respecto? ¿Por qué ningún investigador local se planteó posteriormente el desarrollo de modelos experimentales? Está claro que las evidencias experimentales modernas plantean el hecho de que Carrión no pudo llegar a la anemia grave a partir de la inoculación, a menos que sea portador de una enfermedad que lo hiciera padecer de una alteración del RES * $\left({ }^{32-34}\right)$. Ello implica que Carrión sufría de un nivel de padecimiento o de una enfermedad previa que llevase a esta alteración ${ }^{\dagger}$. ¿Esto era desconocido por Carrión o por quienes lo acompañaron en la experiencia? La reacción virulenta de sus condiscípulos respecto a la comparación entre los hallazgos de la autopsia de Carrión y los observados en una paciente tuberculosa fallecida por verrugas pocos días después, apuntan a soslayar cualquier duda frente a la condición física de éste. Sin embargo, hasta ahora sabemos que hasta el momento, las distintas autoinoculaciones no han podido reproducir la historia natural de la enfermedad alcanzada por Carrión $\left({ }^{35}\right)$. Todo ello refuerza el carácter mítico de la experiencia y su elaboración como una construcción cultural.

Un hecho sumamente singular es el proceso judicial contra Evaristo Chávez. Allí, el Agente Fiscal de Lima el abogado José Aniceto Carvajal señala:
"Con el abnegado sacrificio de Carrión se ha descubierto dos principios:

1. “Que la Verruga es transmisible por inoculación.

2. "Que esta enfermedad y la llamada Fiebre de la Oroya no son sino dos períodos de una sola y misma dolencia o como se expresa en lenguaje técnico se ha comprobado la unidad etiológica de ambas enfermedades..."

Sin embargo el fiscal va más allá y afirma lo siguiente:

“Una última reflexión para concluir lo relativo a la calificación legal del hecho realizado por Carrión. ¿Cómo puede explicarse que el niño verrugoso, de cuya sangre se hizo uso para inocular aquella enfermedad, presentase una marcha benigna, hasta el punto que se le diese por enteramente curado, y ese mismo virus, inoculado a Carrión, produjera una enfermedad de carácter grave y mortal? El germen morboso era el mismo y, sin embargo, los resultados fueron totalmente opuestos. Esto manifiesta que cada organismo tiene su modo de ser especial; y que un principio morboso puede producir tales o cuales fenómenos, según sea la peculiar constitución del terreno en que va a germinar..." $\left.{ }^{(36}\right)$.

Mackehenie, 57 años después, fue el primero en reparar en este hecho, señalando: “ $¡ M a r c h a$ normal y benigna, un mismo germen morboso produce resultados diversos, una peculiar constitución y terreno profesa en 1885 un Doctor en Leyes en esta capital!... Gracias al proceso instaurado contra el Dr. Chávez... conocemos tan interesantes opiniones, avanzadas, quizás revolucionarias para la época, las del señor Fiscal..." $\left.{ }^{(37}\right)$.

Es evidente, la imposibilidad que el fiscal pudiera por sí mismo alcanzar tal nivel de abstracción y comprensión tanto de los procesos de análisis causal, inoculación y mecanismos de regulación inmune, según lo que se desprende de sus sorprendentes tesis. ¿Cómo un abogado de 1885, que con toda seguridad tuvo en el proceso judicial sobre la muerte de Carrión su primera aproximación a estos problemas experimentales totalmente ajenos a su praxis intelectual, pudo llegar a semejantes conclusiones, si la mayoría de los médicos del colectivo local no manejaban dicho nivel de abstracción e información? Es sumamente

* Oscar Urteaga planteó un enfoque crítico de la experiencia: “Carrión nunca afirmó que moría de Fiebre de la Oroya y él no puede ser responsable de su autopsia. Han sido otros los que con criterio nacionalista, sin darse cuenta deformaban el avance científico. El sacrificio de Carrión queda incólume y su renunciación constituye la página más brillante de la medicina nacional..."; a pesar de reconocer el aporte de Carrión como realización cultural, Urteaga, al dar a conocer sus opiniones, recibió públicamente duras críticas por las autoridades de la Facultad de su época. Es interesante que exista toda una tradición oral respecto a opiniones similares, las cuales nunca han sido analizadas y discutidas públicamente, por temor posiblemente a repetir reacciones como las generadas por las tesis de Urteaga.

$\dagger$ Los médicos de la policía que investigaron la muerte de Carrión sostuvieron que éste padecía previamente de verrugas, sin citar la fuente de su afirmación, la cual fue desmentida por sus compañeros. 
probable, que el fiscal se haya limitado a reproducir, las reflexiones de quienes manejaban la sistematización en torno a la historia natural de la verruga, quienes en el fondo eran quienes probablemente habían ideado y organizado la experiencia. Las tesis del fiscal, que permiten exculpar de toda culpa al Dr. Chávez y por ende a la Academia, constituyen la mejor prueba de la existencia de una concertación de voluntades, confluyentes a la construcción del mito en medio de un escenario de enfrentamiento y lucha por el poder $*\left({ }^{38}\right)$.

\section{CARRIÓN COMO BASE DE LA CONSTRUCCIÓN DEL IMAGINARIO MÉDICO Y MOVIMIENTO CULTURAL}

El experimento de Carrión desde el inicio se vio envuelto en una controversia, dado que ingresa rápidamente en el contexto del conflicto entre la Facultad (Iglesias) y la Academia Libre de Medicina, la cual en vista de su oposición a Iglesias, era empujada a la esfera política de Cáceres. Sólo así es posible entender la posición sumamente dura de la Facultad y cómo la Academia Libre de Medicina, a pesar de haberse desentendido de Carrión durante su experimento, cierra filas en torno a su figura, llevando el luto en el cortejo fúnebre. Es claro que el reconocimiento de Carrión sólo es posible en el marco del triunfo militar de Cáceres, que permite el retorno de los docentes que habían abandonado la Facultad por la intervención de Iglesias y que habían hecho suyo a Carrión.

Sin embargo, ese contexto de conflicto, que ahora se ha perdido de vista, es la clave para entender cómo se construye o se reelabora la imagen de Carrión. En ese momento, la Facultad tenía la excelente oportunidad de desprestigiar a sus opositores como promotores de un acto aventurado que trajo la muerte a un incauto estudiante. La estrategia de la Academia Libre de Medicina fue desde el inicio colocar la acción de Carrión en el plano de la experiencia positiva y recalcar (como lo revela la defensa que hace Villar), en el marco de la investigación criminal, que el experimento del joven mártir es parte de una corriente cultural, de una forma romántica de ejercicio de la ciencia, tal como se realizaba en Europa. Corrobora ese hecho la forma como la Academia coloca a Carrión a la par del imaginario europeo, como lo expresa Macedo durante sus exequias:
"El nombre de Carrión pasa a la historia y con iguales títulos que los venerables nombres de Jenner, Pasteur, Ferrán y Freire; se repetirán de siglo en siglo con la gratitud de los hombres de corazón..."

Seguido, luego de un año, aparece la publicación preparada por sus condiscípulos, editada en la Imprenta del Estado, donde se hace a través de un conjunto de testimonios una reconstrucción del experimento, una cronología de los hechos, así como la publicación de las historias clínicas que constituían, según sus condiscípulos, la base sobre la cual Carrión delineó su experimento. Es evidente que, al margen de los acontecimientos, existe un relato particular de los mismos por parte de los actores, el cual, como lo plantea Fleck, no necesariamente puede corresponder a la realidad, sino a la lectura o interpretación del colectivo de los hechos $\left({ }^{39}\right)$ y a la necesidad, en medio del desastre material y moral del país, de encontrar referentes que reconstruyan nuestra autoestima, en un campo en el cual no poseíamos ninguna tradición, como la ciencia experimental.

Carrión así pasa a ser el inicio de una corriente cultural, en la cual la investigación no solamente es cada vez más importante sino que además tiene legitimidad social, como parte del proceso de reconstrucción nacional. El interés por continuar con "el legado de Carrión" hace que la Bartonellosis sea la enfermedad más investigada en toda la historia de la Medicina Peruana, pero, por sobre todo, durante los siguientes 50 años posteriores al sacrificio de Carrión $\left({ }^{6,40}\right)$.

Esta corriente cultural expresada en las investigaciones sobre la Enfermedad de Carrión confluye con la inserción del positivismo promovida por las élites gobernantes como uno de los motores de la reconstrucción y modernización del país. Seguidamente emerge el indigenismo, expresado por la revalorización de lo andino y por un énfasis en el estudio de nuestros problemas por los investigadores peruanos. Existe una continuidad entre el Carrionismo y positivismo a finales del siglo XIX con el indigenismo y el biologismo flexneriano de los treinta, lo que al final nos deja un ciclo de 70 años, que constituyen el ciclo de lo que comúnmente se denomina "Escuela Médica Peruana", que corresponde al mayor período de desarrollo científico institucional y cultural de la medicina en el Perú. Ello es expresado meridianamente por Lastres quien, respecto a la trascendencia del aporte de Carrión, refiere:

* Las siguientes consideraciones del fiscal son sumamente explícitas “...en el presente caso, no debe prescindirse del fallo de la opinión pública ha formulado respecto a la empresa acometida por Carrión. Unánimes han sido los aplausos y elogios que se le han prodigado todos los periódicos, haciéndose intérpretes de esa opinión, le han dedicado sentidos y encomiásticos artículos, doctas asociaciones, como la 'Academia Libre de Medicina' y la 'Unión Fernandina' tienen como un honor considerarlo en el número de los socios presentes y en la actualidad, se lleva a cabo una suscripción popular con el fin de erigirle un mausoleo, que perpetuando su memoria, lo recuerde a las generaciones venideras como un mártir de la ciencia..." 
"Tal fue el panorama que vivió Carrión, la opulencia y el desastre, la grandeza y la ruina de nuestras instituciones médicas. Pero su espíritu acostumbrado a la lucha dio el impulso definitivo a la investigación, proporcionó la levadura de la que ha vivido ella durante más de 70 años. Es justo decir que el sacrificio de Carrión marca una etapa ascensional en nuestro standard cultural y que, después del desastre nacional, el triunfo como Cajal después del '98 español, procurando nuevos lampos de gloria para el Perú..." $\left({ }^{41}\right)$.

Sin embargo, la asimilación del positivismo como corriente cultural asociada al mito fundacional representado por Carrión no fue institucionalizada, es decir, fue un discurso que no se acompañó de la inserción, tanto de un sistema u organización que hiciera posible el trabajo científico, como de una cultura que asimilara la ética del trabajo detrás de la filosofía positiva. Una muestra de cómo la universidad asimila institucionalmente este movimiento cultural lo muestra descarnadamente Cueto, cuando describe las condiciones con que se realizaba la ciencia en la Facultad al principio de siglo:

“La investigación surgió, pero permaneció como una empresa marginal. No existió continuidad en los esfuerzos por hacer de la investigación una actividad sistemática. No es posible hablar de una profesionalización de la investigación para este periodo. La mayoría de los científicos no pudieron serlo a tiempo completo y esto impidió la formación de una verdadera comunidad científica. La mayoría de los científicos eran médicos y debían de cumplir misiones rutinarias en hospitales y consultorios. Como revela un destacado científico de la época, utilizaban su tiempo libre en el hospital para realizar los cultivos de verruga. En un país poco industrializado y con fuertes inversiones de tecnología y capital extranjeros, existía poca demanda por obtener nuevos logros científicos y tecnológicos. Todo esto se reforzó además por que la educación superior y la cultura oficial tuvieron un signo elitista $y$ ornamental, donde no encajaba totalmente la labor científica profesional, menos aún si no tenía una aplicación práctica segura..." $\left({ }^{42}\right)$.

En este escenario, quienes realizaban investigaciones en la enfermedad de Carrión enfrentaban enormes dificultades, las cuales eran superadas sobre la base de una gran persistencia y compromiso, tanto por los contemporáneos de Carrión, como por sus discípulos. Un ejemplo de ello, lo expresa Julián Arce, condiscípulo del mártir de la medicina peruana, cuando le refiere al presidente de la comisión organizadora del $6^{\text {to }}$ Congreso Médico Panamericano a realizarse en Lima:

"Los trabajos sobre la etiología de la Verruga y de la Uta encomendados... continúan con actividad y empeño, aunque con la amplitud que sería desear, dada la importancia y trascendencia del fin que se persigue. En efecto, no contando con elementos propios ni con recursos que exigen estudios de esta clase, hemos empezado la labor con un microscopio y con un hemoglobinómetro prestados por el señor decano de la Facultad de Medicina, completando las operaciones de laboratorio ya sea en el Instituto de Higiene Municipal, ya en el Instituto Nacional de Vacuna y Sueroterapia. Este procedimiento complicado y deficiente, no sólo embaraza los trabajos y ocasiona pérdida de tiempo, sino que limita el número y la calidad de las investigaciones. Por otra parte, el material de estudio está reducido a los pocos enfermos que ingresan a mi servicio del Hospital Dos de Mayo, pues la carencia de recursos no nos permite extender nuestro trabajo a las zonas infectadas..." $\left({ }^{43}\right)$.

$\mathrm{Si}$ éstas eran las condiciones con que se investigaba la enfermedad más importante del país, en tanto su connotación histórica y social, podemos imaginar el poco interés de las instituciones médicas por impulsar y consolidar la investigación científica como elemento central de la praxis del colectivo médico. La pregunta que surge aquí es, ¿por qué llegamos a ello?

Una primera aproximación parte de la forma cómo se asimiló el positivismo por la comunidad médica local, la cual decodificó de una manera muy particular la filosofía positiva que impregnaba la clínica francesa de la segunda mitad del siglo XIX, que era el referente cultural más importante de la Medicina Peruana de ese entonces. Más que una cultura de generación de conocimiento para una nueva visión del mundo, se convirtió progresivamente en un discurso, es decir, el positivismo fue reelaborado, convirtiéndose en una ideología. La posterior incapacidad de la facultad de medicina de asimilar e institucionalizar las ciencias básicas, motor fundamental de los avances de la medicina y el progresivo deterioro de investigación, convirtió la actividad científica institucional en una nueva escolástica $\left({ }^{44}\right)$.

A inicios de la década del veinte se observa que la investigación en enfermedad de Carrión, por parte de los investigadores nacionales, decae notablemente, siendo el conocimiento más importante en verruga producido por investigadores extranjeros $\left({ }^{45}\right)$. Un proceso que se observa claramente, además del declive de las investigaciones nacionales en verruga peruana, es el establecimiento claro de una ciencia "oficial" propia de la arquitectura estamental de la Facultad de Medicina $\left({ }^{46}\right)$, que se mantiene hasta hoy como una muestra de la premodernidad de nuestra institucionalidad académica. Ello lo expresa claramente Pedro Weiss, cuando relata el contexto de cómo inició sus investigaciones en Verruga: 
"Aquí en el Perú a la gente le gusta apropiarse de las cosas. Uno es dueño del corazón, otro del riñón, un tercero del páncreas y así sucesivamente. Cuando regresé, lo único que encontré sin dueño era el retículo-endotelio. De ahí salió la Verruga..." $\left({ }^{47}\right)$.

Ello implica la existencia de una ciencia oficial, conservadora del status quo y de las jerarquías, aquellos que Aldana denominó "Verrucólogos Oficiales". Esta fragmentación, explica por qué el movimiento cultural que significó las investigaciones en enfermedad de Carrión, no pudo cuajar en una institucionalidad relevante para el desarrollo de la ciencia en el país, y cómo hasta ahora las propuestas de investigación no pueden superar a la existencia de las personas; casos como los de Weiss, Monge, Gutiérrez Noriega, Lumbreras, entre otros, son una muestra de una interminable lista de ejemplos de ello.

Todo lo anterior nos muestra que el escenario socio cultural de principios del siglo pasado fue el que hizo posible la aparición de dos generaciones que tuvieran una visión particular de la ciencia y del país $\left({ }^{48,49}\right)$, en un momento de cambios producto de la posguerra y la asimilación del Perú a la economía industrial de principios de siglo, la cual venía de la mano con el pensamiento positivista, que fue uno de los ejes de la modernización del país. Esa generación pudo producir conocimiento relevante, a pesar de las condiciones difíciles con las que contaron. La causa de la crisis y ulterior decadencia actual de la escuela médica nacional a partir de los sesenta, radica en que no existió una generación de reemplazo de un nivel semejante que permitiera asimilar y articular institucionalmente al nuevo colectivo médico, los referentes culturales de los investigadores de las primeras décadas del siglo $\mathrm{XX}$.

En el caso de Carrión, éste fue cayendo progresivamente en el olvido, llenando la necesidad de un mito fundacional, el cual es aceptado acríticamente dentro de una hagiografía funcional al mantenimiento del status quo, que a la promoción de un conjunto de valores que se plasmara en una cultura institucional. La ruptura del ' 61 , con todo el significado que tuvo en la medicina nacional, no produjo algún cambio significativo en la lectura de la imagen de Carrión, el cual convertido en un icono neutro, puede ser absolutamente reivindicado por todos los secto- res, al estar absolutamente arraigado en un pasado que no tiene presencia en el presente. La aparición de una serie de lecturas interpretativas respecto a este personaje desde las emergentes, hasta las positivistas $\left(^{50-53}\right)$ tratan de reinsertar a este importante referente dentro de nuevos escenarios institucionales y culturales, con diversos grados de alienación del contexto social y cultural en el cual se desarrolló dicho evento histórico * $\left({ }^{54,55}\right)$.

\section{EL SIGNIFICADO DE CARRIÓN EN EL CONTEXTO ACTUAL}

¿Qué sentido tiene el análisis crítico de este proceso? Es evidente que el escenario de crisis institucional, académica e ideológica, que embarga a la medicina nacional, luego del declive generacional de los exponentes de la Escuela Médica Peruana a fines de los cincuenta, marca la salida del Perú del grupo líder de países de América Latina en el campo de la Medicina, la culminación de una época en la cual médicos peruanos daban conferencias en Universidades y Academias Americanas o Europeas, recibían grados Honoris Causa o eran líderes de opinión en el ámbito latinoamericano, incluso mundial. Esa época marcada por una capacidad de hacer preguntas en la ciencia médica, desde nuestra cultura, con una mirada y personalidad propia, desapareció y con ello se inicia el retroceso continuo de la medicina peruana respecto a los países más avanzados de la región, en un proceso de decadencia y desnacionalización que supera las cuatro décadas consecutivas y en el cual, a pesar de la aparición de numerosas facultades de medicina en el sector universitario público y privado, no existen indicios de que ese proceso se haya detenido, sino al contrario, que la brecha existente entre la práctica de la medicina y la producción de reflexión y conocimiento médico entre los países líderes en América Latina y el Perú se hace cada vez más grande.

Sin embargo, el análisis histórico del colectivo médico nos muestra que el proceso de ascenso de la medicina peruana se inicia con Carrión. El mundo occidental, sobre todo Europa, repara la existencia de un lejano país donde un estudiante muere en un intento por hacer investigación, en los términos del imaginario cultural europeo y por ende de la existencia de una comunidad científica. Este interés se enlaza por un sentimiento de renovación nacional, a

* Un ejemplo interesante de ello es Hugo Pesce, quien en 1957 sitúa el experimento de Carrión en el contexto del positivismo, hablando incluso de una "Heurística Carriónica"; sin embargo, luego de la fractura institucional del " 61 , cuando Pesce se plantea profundizar la línea reformista como una salida de la crisis de la Facultad y para ello recurre al joven mártir “¿Qué mejor inspiración que la del propio Carrión para buscar este fecundo camino... así Carrión fue objetivamente un adalid de la reforma, al haber encarnado en su persona la altísima y privilegiada capacidad de un estudiante de medicina para aunar la sublime docencia ejercida hora por hora desde su lecho fatal, con esos frutos de investigación que el Perú atesora y el mundo admira...” 
través la ciencia positiva, la cual comienza a tener un espacio de legitimidad social, en la medida que, según las elites positivistas, se necesitaba de la ciencia y la técnica para el desarrollo y reconstrucción del país. Por otro lado, la comunidad médica tuvo a Carrión como referente, lo que motivó el desarrollo de una creciente producción científica en torno a la Verruga, enfermedad que en el contexto emergente de la bacteriología en el campo de la ciencia, permitía una gran visibilidad de los investigadores nacionales, lo que condujo a la confluencia de intereses comunes y permitió por primera vez la articulación de la ciencia local al sistema científico mundial $\left({ }^{2}\right)$. En esta etapa, el referente cultural de la ciencia en el país era el positivismo y la capa social aristocrática era el elemento dinamizador que impulsaba la ciencia en el Perú. Un elemento que se inserta en este proceso es la aparición del indigenismo y los movimientos sociales de los años veinte. Por un lado, comenzó a mirarse al Perú con una visión más propia, producto del interés de conocer y revalorizar el país. A ello se sumó una capa social emergente, que comenzó a reconocer la posibilidad de plantearse sus propias preguntas y visiones de la medicina y que a pesar de estar insertos en la medicina de occidente, se reconocían herederos de una tradición propia, una ciencia médica hecha desde la mirada de los peruanos, donde Carrión era el elemento central de dicha tradición.

Sin embargo, el desarrollo de esta corriente cultural no pudo plasmarse en una praxis que pueda ser asimilada por las diversas instituciones. El esforzado trabajo de numerosas iniciativas individuales no pudieron transformar una cultura esencialmente premoderna, caracterizada por una asimilación epidérmica y distorsionada del positivismo, una red dispersa y débil de instituciones, a la par de una facultad de medicina feudal.

Para tratar de entender esta tendencia de deterioro, es necesario regresar al inicio del proceso de inserción de la Medicina Peruana en la tradición médica occidental, cuando la comunidad internacional es conmovida por la noticia de la inoculación de un joven estudiante peruano. Este joven provinciano, de extracción andina, en medio de las privaciones e incertidumbres de un país destruido y en plena guerra civil, decide apostar por un espacio de reconocimiento y legitimidad. Al margen de la cuidadosa preparación e instrumentación del episodio por la Academia Libre como parte de una lucha de hegemonía cultural e institucional local, la muerte no prevista de Carrión tiene un gran impacto en varios niveles. En el ámbito local, se constituye en un referente importantísimo, en un país destruido. Carrión permite un nuevo punto de partida para la reconstrucción de nuestra autoestima como sociedad. De otro lado, Carrión, sin quererlo, con su sacrificio establece un puente que permite una inserción progresiva del colectivo médico peruano en la ciencia internacional.

Sin embargo, ello requirió un proceso complejo de asimilación y recodificación, en la medida que la accidental trascendencia del provinciano Carrión (el "cholo" Carrión que señala Uriel García) en medio de la disputa de dos facciones aristocráticas de la Facultad, fue una salida de coyuntura en un conflicto que expresaba las contradicciones sociales y de grupo generadas por la guerra civil. Como resultado de ello, el sector más aristocrático retoma el poder en la Facultad. Sin embargo, tuvo que transformar al mártir en una figura que pudiera ser asimilada por la élite blanca, en función de moldes culturales, sociales, políticos, incluso antropomorfos *, fuera de su realidad concreta y contexto local $\left({ }^{18,56}\right)$ (Ver Figura). Este elemento de alineación racial es importante para establecer el carácter de construcción del mito de Carrión, dado que la élite blanca no podía aceptar el carácter andino de este último, dado que el racismo era un componente importante de la ideología dominante $\left(^{2}\right)$. Estamos hablando de gente que identificaba a los habitantes del ande como una raza abyecta y degradada, como una de las muchas castas que infestaban al Perú, o simplemente que la mejor solución para el país consistía en exterminar a los indios a balazos, como a los Pieles Rojas en los Estados Unidos $\left({ }^{57}\right)$.

Por todo ello, el mito fundacional de la Medicina Peruana, que establece el puente entre lo nacional y lo universal en la cultura médica de Occidente, fue un reflejo de la élite criolla blanca, la cual había hecho suyo el proyecto institucional de Cayetano Heredia, el cual fue un espacio de ascenso social de las clases emergentes mestizas, que encarnaba este último y que no pudo sobrevivir a la desaparición de su promotor, con lo que San Fernando retorna a su raigambre aristocrática inicial, a pesar del carácter social emergente de su fundador Hipólito Unanue $\left.{ }^{58}\right)$. A fines del siglo XIX, el proyecto de la naciente medicina nacional posterior a Carrión era el proyecto cultural de la élite blanca dominante.

El ascenso del grupo social emergente en el campo de la medicina se hizo en el marco de esta impronta cultural, la cual era sumamente fuerte, dado que estaba enlazada al status quo institucional, a los grupos aristocráticos que manejaban la estructura feudal de cátedras de la Facultad,

* La figura de Carrión fue rápidamente transformada a efectos de la construcción. La Crónica Médica publica un grabado que inicia el proceso de metamorfosis que culmina con el Carrión casi blanco de Lastres. De este retrato Flores señala "que su atractiva figura juvenil está muy bien representada”. Un grabado semejante aparece en El Perú Ilustrado del 12 de noviembre de 1887. 


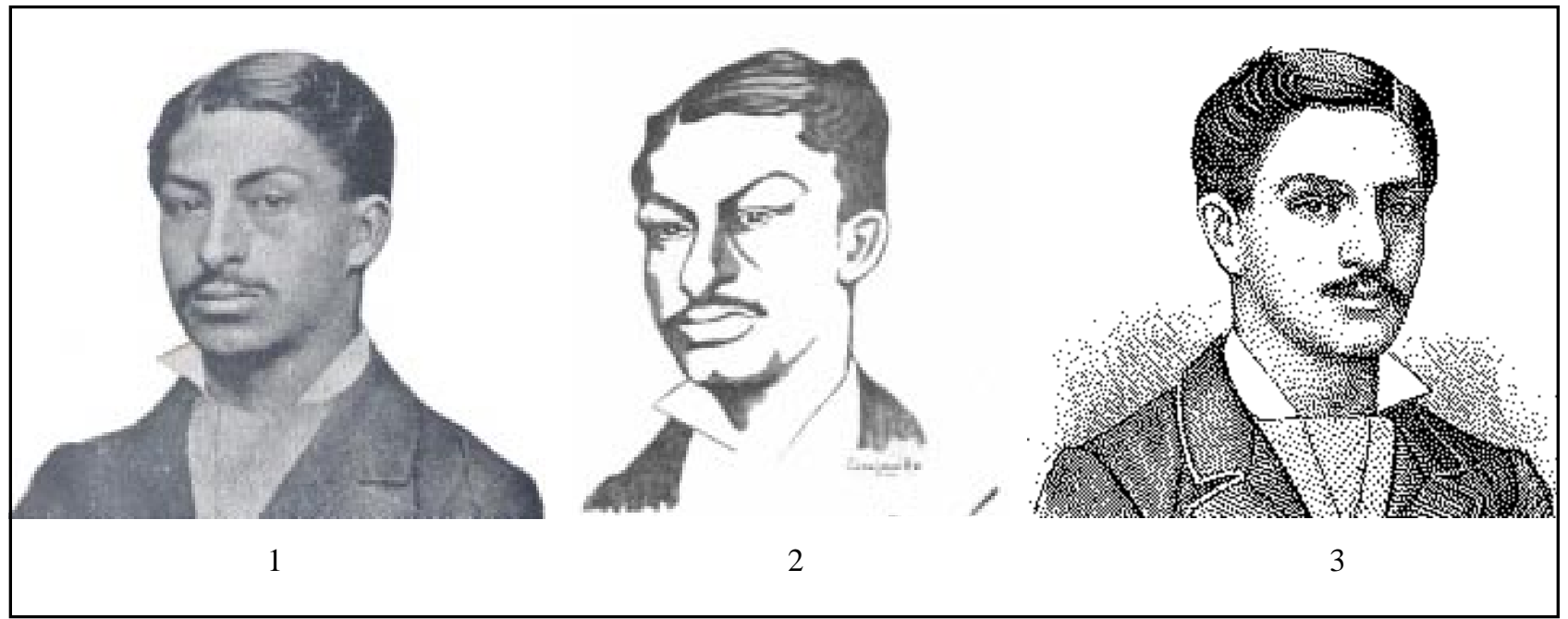

Figura. 1) Obsérvese las diversas lecturas que ha tenido la imagen de Carrión, expresada fielmente por la litografía de Courret. 2) En el centro, una representación iconográfica publicada en la década del ' 50 , de corte indigenista, representa en el fondo, la plasticidad de la imagen de Carrión en función de diversos discursos y representaciones culturales. 3) Nótese la profunda transformación del grabado publicado por Odriozola, donde se transforma la imagen de Carrión en términos étnicos europeos, más fácilmente asimilables para las élites blancas criollas, siendo ésta la imagen que asume el colectivo local e internacional.

dentro de las prerrogativas que manejaban las capas sociales dominantes. El ascenso de los grupos emergentes en la medicina, a partir de la nueva fisura social creada por Carrión, está marcado por la cultura dominante en la Facultad, a pesar de la fuerza del indigenismo y los movimientos sociales de la década del veinte $\left({ }^{59}\right)$. Sin embargo, existía toda una corriente social que, a pesar de la tradición de la medicina occidental y de un positivismo que llevó a un darvinismo social y a discursos eugenésicos $\left({ }^{60}\right)$, que incluso llegaron a sensibilizar a elementos progresistas de la clase médica $\left({ }^{61}\right)$, llegó a trazar elementos dirigidos a crear el espacio para una medicina mestiza, como el monumental proyecto de Hermilio Valdizán $\left({ }^{62}\right)$. Brillantes sanfernandinos, social y étnicamente emergentes como Carlos Monge, a pesar de la influencia del indigenismo, tuvieron como referente cultural a occidente (de hecho, muchos de ellos tuvieron formación de posgrado en escuelas europeas o norteamericanas) y, a pesar de la originalidad de su visión del mundo y los problemas de investigación que lograban proponer, no lograron plasmar institucionalmente una medicina mestiza y sincrética $\left({ }^{63}\right)$.

En el caso de Carrión, a finales de los cincuenta, su figura se transformó en el imaginario del colectivo médico de una guía para la reconstrucción de la facultad y del país, en un icono funcional para academias y ceremonias $\left({ }^{59}\right)$, como lo menciona García "Escribir, investigar, divulgar o simplemente encomiar la figura de Carrión otorgó prestigio y constituyó una marca de buen ejercicio profesional para una buena parte de la élite médica nacional" * $\left({ }^{64,65}\right)$.

La crisis del '61 fue consecuencia del desfase de una facultad que había devenido en anacrónica frente a los cambios acelerados de la sociedad y sus instituciones. La Facultad de Medicina, a pesar de la participación política de algunos de sus profesores, al ocupar cargos ministeriales en el gobierno de Bustamante (Honorio Delgado y Alberto Hurtado) y el profundo desprestigio de algunos personajes, como el Decano Oswaldo Hercelles, considerado como

* Una muestra de ello lo tenemos en un precoz líder de opinión de la medicina post Carrión, en 1889, año que Ernesto Odriozola se incorporó a la "Sociedad Médica Unión Fernandina", la misma que le tributó un magnífico homenaje público en el que le entregó una tarjeta de oro y lo eligió miembro honorario por su libro "La Maladie de Carrión". En ese acto, el Dr. Enrique León García hizo la historia de la enfermedad de Carrión en la cual estableció con mucho acierto "El período Odriozola, período de luz y de cabal conocimiento de la enfermedad misteriosa". 
títere del hombre fuerte del gobierno de Odría, EsparzaZañartu $\left.{ }^{66}\right)$, había logrado cierta estabilidad frente a los graves problemas que tuvo la Universidad de San Marcos en la década de los cincuenta, de hecho, constituyendo un hinterland aristocrático en una institución cada vez más abierta a los sectores populares. Un elemento central en la crisis del ' 61 , al margen de los conflictos específicos, fue el ascenso de la clase emergente a la conducción de la Facultad de Medicina San Fernando, además del acceso a la misma de un porcentaje mayor de alumnos procedentes de sectores populares. Esta dinámica produce un cambio cultural que es clave para entender la crisis de la figura de Carrión en el imaginario institucional y social.

El sistema aristocrático de la Facultad era un sistema estamental basado en los derechos adquiridos, los cuales incluso podían ser hasta hereditarios. Sin embargo, en este sistema existían mecanismos de movilidad, basados en acuerdos de consenso y acreditación académica. Evidentemente, existían manejos e intereses que, sin embargo, tenían un estándar mínimo de acreditación y también de productividad intelectual de sus líderes, los cuales explicitaban un discurso de humanismo aristocrático $\left({ }^{67}\right)$. Este sector, heredero cultural de los positivistas de principios de siglo, entendía la ciencia como un elemento propio de su carácter de élite y en ese contexto la imagen de Carrión, codificada en los términos de su imaginario cultural, tenía sentido en el marco de una misión institucional.

El sector emergente que ingresa a la conducción de la Facultad en el ' 61 hace su propia lectura y apropiación del sistema feudal, que era el núcleo de la dinámica institucional, el cual devino en un sistema patrimonialista de cátedras y espacios académicos. El discurso modernizador de la crisis del ' 61 fue sobrepasado por dicha decodificación, la cual, en el marco de una cultura premoderna, se planteó con códigos eticomorales caracterizados en las conductas sociales de los segmentos emergentes $\left({ }^{68,69}\right)$, que Seguín describe muy sentidamente en su conocida entrevista con Max Silva $*\left({ }^{70}\right)$. En ese escenario, la imagen de héroe cultural de Carrión, impulsada por los positivistas de fines del siglo XIX y principios del siglo XX, fuera del contexto y los códigos culturales de sus creadores, devino en un icono intrascendente, continuando en su papel funcional para ceremonias y homenajes.

Pesce, en su preocupación por crear una base cultural para el desarrollo de un nuevo proyecto institucional, fue el primero en trabajar la reelaboración del mito y a ello apunta su discurso de Carrión y su positivismo científico, tratando de reintroducir el ideal cultural de la ciencia en el contexto social de San Fernando. Sin embargo, esta propuesta no pudo ser asumida por el colectivo sanfernandino después de la crisis del ' 61 , dado que la ciencia no tenía ni tiene hasta hoy mayor relevancia en la matriz cultural de los sectores emergentes en un contexto sociocultural diferente, los cuales plantean otro tipo de reivindicaciones y aspiraciones, además de tener una lectura más pragmática de su relación con la institución. Ello es una de las causas que explican el deterioro de la producción científica y el nivel intelectual de diversos sectores y estamentos académicos nacionales.

La pregunta que surge aquí es ¿en qué medida la figura de Carrión puede ser relevante para la Medicina Peruana en el siglo XXI?

La trama social del colectivo médico de finales del siglo $\mathrm{XX}$, es fundamentalmente del sector emergente de la sociedad. Este sector se inserta socialmente a la medicina con Carrión, un estudiante que logra trascender sobre la base de la impronta social y cultural de este grupo, que encuentra ahora, al inicio del siglo XXI, un escenario similar a la posguerra de fines del siglo XIX, donde se plantea la necesidad de reconstruir y refundar el país, sus instituciones, de tener que apostar a nuevas prácticas, paradigmas y formas de organización social, para poder trascender y surgir material y profesionalmente, como lo expresa meridianamente García:

"Carrión es el Peruano mestizo, estudiante de medicina, cuya figura y acción es producto de una contrastante suma de factores. La baja calidad de los estudios universitarios, la imperfección de la técnica a su disposición, la pobreza económica, su origen serrano, la caótica situación política y social de entonces, su imaginación creativa y su deseo de superación, en medio de un ambiente mediocre, se sumaron en lógica mezcla, sobre él, para ejercer su influjo y empujarlo a realizar lo que hizo..."

"Carrión no es el héroe epónimo que consciente de su deber histórico se lanza a la inmolación. Tampoco es el hombre de ciencia paciente y frío que se olvida de su propia persona durante la abstracción de un experimento que le cuesta la vida. No, Carrión es nada más y nada menos que el cholo peruano. Esto es lo que hay que exaltar en él. Su peruanismo puro, imaginativo, pero falto de recursos y formación académica. Intuitivo, pero atrevido hasta la imprudencia. Y no se podía ser de otro modo en el Perú de 1885. Con una universidad arruinada, sin biblioteca, la-

* Cuando Max Silva le pregunta a Seguín por su paso por San Fernando en el turbulento período poscrisis del '61 refiere “... Si hay un tema que no desearía tocar es éste. Está tan lleno de sufrimientos y, más que ello, de desilusiones y de -lo que fue para mí inmensamente más doloroso- choques con una realidad que me ha mostrado, una y otra vez, a los hombres en lo más pobre de su humanidad...” 
boratorios, profesores idóneos y, sobre todo, sin el ambiente de "serena paz" propicio para la investigación, como lo dijo Pasteur. Así no podía surgir por generación espontánea un científico cabal. Si hoy, a casi un siglo de entonces, el criollismo aún domina las actividades académicas de la nación..." * $\left.{ }^{71,72}\right)$.

¿Cómo una cultura resistente y de supervivencia como la que ostentaba la capa social mestiza emergente que dio origen a Carrión, pudo haber sido el motor que haya llevado a la medicina peruana por 70 años al mayor desarrollo técnico y legitimidad social de su historia, al punto de colocarla en un determinado momento en un lugar preeminente en el concierto latinoamericano? Planteamos la hipótesis de que, en el caso particular de Carrión, se dio la posibilidad de una articulación cultural con occidente que nos permitió por primera vez una inserción global desde lo local, la posibilidad de ser protagonistas del imaginario científico cultural de Occidente, no desde la imitación, sino desde nuestro propio discurso, desde nuestros propios problemas y limitaciones. Sin embargo, para lograr ello en un país como éste, se requirió la misma matriz cultural que lleva a una madre de un comedor popular a luchar por la supervivencia de sus hijos, o que permite que la gente pueda vivir en el arenal y construir ciudades y escuelas. Esa misma matriz cultural permitió que gente, como Sebastián Barranca, Escomel, Arce, Tello, Valdizán, Monge, Weiss, Seguín y otros mil, como lo señala la letra del himno de San Fernando, pudieran hacer investigación en medio de la soledad intelectual, pobreza económica, inestabilidad política, la anomia, indiferencia, cuando no ignorancia y hostilidad de las instituciones del país. Fue esta matriz cultural la que permitió que en San Fernando, entre 1886 y 1956, se produjera la mayor cantidad y calidad de conocimiento y reflexión intelectual de toda la historia de la Medicina Peruana.

Sin embargo, la imagen de Carrión y la matriz cultural emergente por sí solas no pueden explicar totalmente el proceso de construcción social y cultural de la escuela médica clásica peruana. En el proceso existió también un elemento crucial en el imaginario colectivo médico; fue la misión histórica de la reconstrucción de la facultad, de reconstruir el colectivo y proyecto original de San Fernando, de recuperar nuestra antigua cultura sanfernandina. El proyecto histórico de la reconstrucción es fundamental para entender la respuesta de los sanfernandinos de principios de siglo pasado, el cual Valdizán logra enunciar con claridad meridiana:
“... Procuremos que la obra de los UNANUE, de los HEREDIA, de los Ríos, de los Odriozola, no se derrumbe definitivamente, Salvemos aquella obra: vayamos a la docencia rodeados de nuestra aureola de pobreza de recursos, envueltos en el manto de nuestra vocación docente. Vayamos a una Escuela de Medicina cuyos maestros y alumnos, orientadas sus actividades en el mismo sentido de rehabilitación de valores ético sociales que si no se han perdido, están a punto de perderse, procuraremos salvar la obra en peligro. Vayamos a esa Escuela de Medicina, cuyo ambiente pedagógico alejará la posibilidad de la brisa política... Y vayamos a esa escuela, representativa del período romántico de la evolución universitaria, porque ella es el único puente fácil y grato que debe separar la catástrofe, de la reconstrucción. Y vayámonos a ella, porque sólo ella puede restablecer, en los claustros de la Escuela de Medicina, aquel ambiente de respeto y de cariño que reinó entre los viejos fernandinos y los viejos maestros..." $\left.{ }^{73}\right)$.

Mito fundacional, resistencia emergente, proyecto de reconstrucción y restauración académica, ética y moral; esta conjunción de valores e ideales, fue la que hizo posible la aparición de la Escuela Médica Peruana y por ende el mayor desarrollo y legitimidad social de la medicina en el Perú. Cuando el mito se convierte en funcional sólo a ceremonias, cuando la resistencia de los emergentes y sus anhelos de superación se convierten en achoramiento, es decir, en una forma de lograr y ejercer el poder, cuando la reconstrucción pierde sus componentes éticomorales, viene la crisis. Estos valores permitieron a la Facultad de Medicina de San Fernando sobrevivir no sólo a la guerra, sino a dictaduras militares y civiles, además del cisma del '61. La pérdida de este imaginario colectivo, de estos valores e ideales fue la causa de la penosa e irrepetible historia de las últimas décadas de la Universidad. Su recuperación será la piedra angular de cualquier proceso de reconstrucción, tanto de San Fernando como de la medicina nacional en su conjunto. Sólo en ese contexto tiene sentido analizar la historia de un joven estudiante provinciano, quien, sin imaginarlo, contribuyó como nadie a la Medicina del Perú y que ahora, como hace más de 100 años está dispuesto a apostar por este proyecto, a darnos su mano en medio de la ruina moral y académica, de las brumas de la anomia y la incertidumbre, a señalarnos el camino, que nos llevará, si tenemos el mismo coraje, sacrificio e imaginación, a construir un colectivo del cual Carrión, Unanue, Heredia, Valdizán, Paz Soldán y otros sanfernandinos ilustres del pasado se sientan orgullosos, como una contribución a la refundación y construcción de un nuevo país.

* En la actualidad, el criollismo al que se refiere García es tipificado por otros autores como achoramiento, definido como una estrategia de ascenso social basada en un pragmatismo maquiavélico y en la mercantilización de las relaciones humanas. El análisis de las primeras evidencias empíricas de "Achoramiento Médico". 
Este análisis debe leerse como una apuesta al futuro. No es el sentido de este ensayo desmerecer la figura de Carrión ni señalar conspiraciones, las cuales no pueden ser vistas aisladas del dramático escenario de conflictos de la posguerra. Nuestra propuesta apunta a recuperar la imagen de héroe cultural, planteando que es posible volver a generar una corriente cultural que permita el resurgimiento de la medicina peruana y una nueva reinserción a la medicina global. Consideramos que el actual contexto socio-cultural es similar al de la posguerra y, por lo tanto, es posible recuperar todo lo que significó el Carrionismo, como un movimiento que permitió el despegue de la facultad e integrarlo a una propuesta de nueva universidad que responda a las expectativas de la sociedad y que contribuya, como lo imaginó Unanue, a la restauración el Perú.

\section{AGRADECIMIENTO}

Los autores expresan su agradecimiento a la Biblioteca de la Facultad de Medicina - UNMSM por las facilidades brindadas, al Dr. Marcos Cueto por su invalorable apoyo y aliento. A los Drs. Eduardo Zárate y Guillermo Contreras con quienes intercambiamos nuevas ideas y recibimos valiosas críticas y sugerencias. Asimismo a los alumnos del curso de Historia de la Medicina con quienes discutimos muchos de los tópicos del ensayo, creando un espacio de reflexión que pretende seguir aportando al crecimiento de nuestra institución.

\section{BIBLIOGRAFÍA}

1. Manrique N. La Piel y la Pluma. Escritos sobre literatura, etnicidad y racismo. CIDIAG-SUR 1999.

2. Cueto M. Excelencia científica en la periferia. Actividades científicas e investigación biomédica en el Perú 1890-1950. GRADECONCYTEC, 1989.

3. Valdizán H. Apuntes para la historia de la Verruga Peruana. Apuntes para una bibliografía peruana de la Enfermedad de Carrión. An Fac Med, Número Extraordinario, $1^{\circ}$ de octubre de 1925: 45-106.

4. Crónica de la Facultad. El Museo Daniel A. Carrión: Cartas y Documentos. An Fac Med 1954; 37(4): 784-814.

5. Barandiarán L. Medio siglo de cultura. El aporte peruano en el campo de la medicina. Rev Sanidad Policía 1950; 10(59): 287 306.

6. Méndez MM. Verruga Peruana. Bartonellaceae. Tesis Br. Programa Académico de Microbiología y Parasitología, UNMSM, 1973.

7. Delgado MG. Daniel Alcides Carrión, mártir de la medicina peruana, héroe nacional. Asociación de Historia de la Medicina-Fondo Editorial UNMSM, Lima 2001.

8. Linares CF. Influencia de la Vida y Obra de Daniel A. Carrión en la historia de la medicina peruana. Tesis Br. Facultad de Medicina, UNMSM 1958.

9. Lanfranco LHC. Notas biográficas de Daniel A. Carrión 18851985. Centenario de su inmolación. Diagnóstico 1985; 16(4): 88-96.
10. Rebagliatti R. Verruga Peruana (Enfermedad de Carrión). Lima: Imprenta Torres Aguirre, 1940.

11. Lastres J. La Medicina en la República. Historia de la Medicina Peruana, Lima: UNMSM, 1951.

12. Avendaño L. Después de 1880. La Crónica Médica, Lima 15 de enero de 1909.

13. Basadre J. Discusión crítica sobre Daniel A. Carrión y su época. Rev Viernes Médico 1973; 34(2): 192-6.

14. Carta de Daniel Alcides Carrión a Alejandro Valdivieso, Lima, 4 de julio de 1885. Crónica de la Facultad. El Museo Daniel A. Carrión: Cartas y Documentos. An Fac Med 1954; 37(4): 784-814.

15. Carta de Daniel Alcides Carrión a Alejandro Valdivieso, Lima, 18 de julio de 1885. Crónica de la Facultad. El Museo Daniel A. Carrión: Cartas y Documentos. An Fac Med 1954; 37(4): 784814

16. Valdivieso A. Carta a Daniel Alcides Carrión, Cerro de Pasco, sin fecha. An Fac Med 1954; 37(4): 784-814.

17. Fdo. Leonardo Villar, Belisario Sosa, Miguel Colunga. Proposiciones aprobadas en la sesión inaugural. El Monitor Médico (Lima) 29 de julio de 1885, pág. 92-93.

18. García CU. Ideas e imágenes en la Enfermedad de Carrión. Análisis historiográfico de la iconografía de la Bartonellosis Humana, Parte I. Folia Dermatol Per 1998; 9(4): 47-54.

19. Villar L. Informe a Sub Prefectura e Intendencia de Policía, Lima 10 de octubre 1885. En Valdizán H. Apuntes para la historia de la Verruga Peruana. Apuntes para una bibliografía peruana de la Enfermedad de Carrión. An Fac Med, Número Extraordinario, 1ro de octubre de 1925: 45-106.

20. Daniel A. Carrión. Carta a su Padre, Lima 26 de setiembre de 1885. Es importante el comentario final que le hace a su padre: "En cuanto se acerquen mis exámenes yo le comunicaré, pues este año me es forzoso salir de la capital. La enfermedad y los estudios me están arruinando bastante..." En An Fac Med 1954; 37(4): 784-814.

21. Historia de la Enfermedad de Carrión, Imprenta del Estado, Lima 1886.

22 Monge C. Discurso de Conmemoración del Aniversario de Carrión, 5 de octubre de 1954.

23. Variedades. La verruga. El Monitor Médico. Lima, $1^{\text {ro }}$ de setiembre de $1885 ; 1(7): 140$.

24. Abnegación por la ciencia. Lima, El Comercio, 29 de agosto de 1885.

25. En La Verruga Peruana y Daniel A. Carrión, Lima, Instituto Sanitas 1957, pág. 39.

26. Arce J. Lecciones sobre la Verruga Peruana o "Enfermedad de Carrión". An Fac Med 1918; 1(4): 24-52.

27. Academia Libre de Medicina, sesión ordinaria del 16 de setiembre de 1886. El Monitor Médico 2(2): 167-9.

28. Editorial. El Monitor Médico 1885; (1): 162-3.

29. Discurso leido por el Sr. Mariano Alcedán, el 05 de octubre del 1886. La Crónica Médica 1886 vol 3(34): 381.

30. García CU. Ideas e Imágenes en la Enfermedad de Carrión. Parte II. Folia Dermatol Per 1999; 10(1): 57-63.

31. Altman L. ¿Quién va primero? Historia de la autoexperimentación en medicina. Barcelona: Editorial Labor, 1990.

32. Finch SC, Jonas M. Ethyl palmitate-induced Bartonellosis as an index of functional splenic ablation. J Reticuloendothelial Soc 1973; 13: 20-6. 
33. Aldana L, Urteaga BO. Bartonellosis post-esplenectomía. Arch Per Patol Clín 1947; 1(2): 289-312.

34. Urteaga BO. Verruga Peruana o Enfermedad de Carrión. Arch Per Patol Clín 1967; 21(3-4): 107-36.

35. Cuadra M, Cuadra AL. Enfermedad de Carrión: Inoculaciones de seres humanos con Bartonella bacilliformis, una revisión. An Fac Med 2000; 61(4): 289-94.

36. Eguiguren L. El Estudiante de Medicina Daniel Carrión (Proceso judicial sobre su gloriosa muerte). Lima, Editorial Ahora, 1942.

37. Mackehenie D. Verruga Peruana, Fiebre de la Oroya, Enfermedad de Carrión o Bartonellosis Carriónica (Historia de un Concepto). An Soc Peruana Hist Med 1943; (1): 13-37.

38. Sección Oficial. La Crónica Médica (Lima) 1885; 2(23): 446.

39. Fleck L. La génesis y el desarrollo de un hecho científico. Introducción a la teoría de estilo de pensamiento y del colectivo de pensamiento. Madrid: Alianza Editorial, 1980.

40. Murillo PJ. Estudio del desarrollo de las investigaciones sobre la Enfermedad de Carrión en el período 1900-1987. Primer Congreso Científico Nacional de Estudiantes de Medicina, Trujillo 20-23 de agosto de 1987.

41. Lastres J. Daniel A. Carrión, Lima 1957, pág. 43.

42. Cueto M. La organización de una cultura científica en Lima: 1890-1930. Apuntes 18, 1986, pág. 129-39.

43. Arce J. La Crónica Médica, Lima 15 de marzo de 1913; pág.87.

44. Murillo JP, Mendoza W, Franco G. ¿Quo Vadis Salud Pública? Discurso y práctica de la Salud Pública en el Perú y su auge universitario en la década de los noventa. An Fac Med 2000; 61(2): 146-60.

45. García CU. Historia crítica de Daniel A. Carrión y la medicina de su época. Tesis Dr. UPCH. Lima, 1972.

46. Lastres J. Historia de la Medicina Peruana. UNMSM. Lima, 1951, pág. 263.

47. Cueto M. Tropical medicine and bacteriology in Boston and Peru: studies of Carrion's disease in the early twentieth century. Medical History 1996; 40: 344-64.

48. Aldana L. Rev Sanidad Fuerzas Polic 1950; 10(60): 307-6.

49. Fernández EE. Pedro Weiss, el hombre. Rev Méd Per 1993; 65 : 37-9.

50. Murillo JP. La obra de Pedro Weiss sobre la Enfermedad de Carrión como contribución al pensamiento epidemiológico nacional. Rev Per Epidemiol 1995; 8(1): 44-53.

51. Arias Schreiber J. La generación médica de la post-guerra del Pacífico. Galeno 1984; 13(155): 36-40.

52. Pesce PH. Carrión y su positivismo científico. An Fac Med 1957; 40: 773.
53. Chiappo GL. Carrión y las motivaciones espirituales de la conducta. En: Trascendencia de Carrión,Lima,UPCH 1986, pág.71-8.

54. Mariátegui CJ. El método científico en Carrión. Rev Viernes Méd 1973; 24: 190-1.

55. Alarcón J. Carrión como científico: Análisis metodológico del experimento de Carrión. An Fac Med 1998; 59(3): 202-6.

56. Murillo JP, Franco G, Mendoza W, Salaverry O. Carlos Lanfranco La Hoz. El final de una época y el inicio de una esperanza. An Fac Med 1999; 60(2): 136-43.

57. Pesce H. Dialéctica póstuma de Carrión. An Fac Med 1966; 49(1): 177-80.

58. Burga M, Flores Galindo A. Apogeo y crisis de la república aristocrática. $4^{\text {ta }}$ Ed. Lima: Editorial Rikchay Perú. 1987: 168.

59. Valdizán H. Fernandinos de Antaño. An Fac Med 1919; 4: 244-50.

60. Manarelli E. Limpias y Modernas. Género, Higiene y Cultura en la Lima del Novecientos. Lima: Ed. Flora Tristán, 1999.

61. Mendoza DS, Martínez O. Las ideas eugenésicas en la creación del Instituto de Medicina Social. An Fac Med 1999; 60(1): 55-60.

62. Mariátegui J. Hermilio Valdizán y la Facultad de Medicina de San Fernando. An Fac Med 1997; 58(3): 222-7.

63. Arroyo LJ. Tradición y nación. A propósito del debate sobre la medicina en el Perú. Alma Mater - UNMSM 1994; 8: 41-50.

64. García CU. La fascinación por Daniel Alcides Carrión y la Bartonellosis. En: SOPHICYT. Hacer Ciencia en el Perú. Lima 1980, pág. 27-40.

65. Ugarte L. Ernesto Odriozola Benavides (1862-1921). Semblanza. An Fac Med 1996; 57(2): 137-8.

66. Mac-Lean y Estenos R. La crisis universitaria en HispanoAmérica. México: UNAM. 1956: 198.

67. Arroyo LJ. La modernización del cientificismo y el arcaísmo nacional actual: El caso de la formación médica en el Perú. Educ Méd Salud 1992; 26(1): 51-69.

68. Ballón JC. Ética, modernidad y autoritarismo en el Perú actual: ¿Vigilar y castigar? Lima: UNMSM-SUR. 1997: 13-23.

69. Ugarteche O. La arqueología de la modernidad. Lima: DESCO, 1999.

70. Silva Tuesta M. Conversaciones con Seguín. Lima: Mosca Azul Editores. 1979: 139.

71. García CU. Historia crítica de Daniel A. Carrión y de la medicina de su época. Tesis Doctoral, UPCH, Lima 1972, pág. 77-8.

72. Medina O. El Achoramiento: una interpretación sociológica. Apuntes de Estudio $\mathrm{N}^{\circ}$ 38. Universidad del Pacífico, 2000.

73. Valdizán H. Elogio del Dr. Ernesto Odriozola. An Fac Med 1922; 5(1):31. 